\title{
Prototype Pengisi Air dan Penutup Botol Otomatis Berbasis Programmable Logic Controller
}

\author{
Rizki Faulianur ${ }^{1 *}$, Zoel Fachri ${ }^{2}$ \\ ${ }^{1}$ Program Studi Mekatronika Politeknik Aceh \\ Jl. Politeknik Aceh, No. 1, Pango Raya, Ulee Kareng- Banda Aceh, Aceh 23119 \\ Corresponding author's e-mail: rizki@politeknikaceh.ac.id
}

\begin{abstract}
Abstrak - Pendidikan vokasi di Indonesia dituntut menghasilkan lulusan yang siap bekerja di pemerintahan maupun Industri. Oleh karena itu pendidikan Vokasi lebih banyak menekankan pembelajaran praktikum. Seperti Politeknik Aceh dengan pembelajaran praktikum $60 \%$ dan teori $40 \%$. Modul praktik yang bervariasi sangat diperlukan untuk mendukung pembelajaran praktik di Politeknik Aceh. Salah satunya Modul Praktikum mata kuliah Programmable Logic Controller (PLC). Untuk menambah variasi modul praktikum PLC, maka dari itu penulis merancang modul praktikum yang menarik agar mahasiswa lebih memahami materi . Modul praktik yang dirancang adalah Prototype Pengisi dan Penutup Botol Otomatis yang bekerja seperti proses di Industri. PLC yang digunakan dari Schneider Elektric tipe Twido dengan seri TWDLCAE40DRF. Alat ini dilengkapi sensor Infrared Proximity sebagai pendeteksi botol, motor konveyor untuk membawa botol minuman, motor DC untuk mengisi air serta solenoid untuk penutupan botol. Mekanik alat ini menggunakan besi Hollow berukuran $3 \mathrm{~mm}$ x $3 \mathrm{~mm}$ dan menggunakan Aluminium Profile pada bagian atas rangka. Hasil yang diperoleh alat ini dapat bekerja dengan baik sehingga dapat digunakan sebagai modul praktikum, mampu mengisi air dalam waktu 14 detik dan mampu menutup tutup botol ukuran $250 \mathrm{ml}$ dengan diameter $3 \mathrm{~cm}$. Walaupun masih kurang mampu menutup botol dengan kuat, alat ini sudah layak dijadikan sebagai modul praktikum PLC.

Kata kunci: Modul praktikum, PLC, konveyor
\end{abstract}

\section{Pendahuluan}

Sistem Pendidikan di Politeknik Aceh menerapkan $60 \%$ praktikum dan $40 \%$ teori. Dengan porsi praktikum yang lebih banyak mahasiswa diharapkan lebih memahami suatu materi perkuliahan. Mata kuliah praktik Programmable Logic Controller (PLC) sedikit sulit dikuasai bagi mahasiswa khususnya program studi Mekatronika karena mahasiswa harus mampu merancang suatu rangkaian kontrol relay kedalam kontrol logika terprogram untuk mengatur suatu proses[1].

Modul praktikum yang telah tersedia di Politeknik Aceh masih perlu dikembangkan untuk meningkatkan pemahaman mahasiswa, karena semakin bervariasi modul praktikum yang digunakan, maka pemahaman materi semakin meningkat begitu juga dengan kreativitas mahasiswa. Pada Penelitian ini dirancang sebuah prototipe pengisian air ke dalam botol dan penutupan botol secara otomatis yang dikendalikan oleh PLC. Pada penelitian sebelumnya telah dibuat sistem pengisian dan penutupan botol otomatis[2]-[4]. Namun pada penelitian ini berbeda dengan penelitian sebelumnya dari aspek design mekanik dan sistem kerja alatnya. Pada alat ini mekaniknya menggunakan konveyor untuk pengisian air dan piringan yang berfungsi untuk membawa botol untuk ditutup.

Alat ini diharapkan mampu melengkapi alat praktikum pada Laboraturium Otomasi Industri Program Studi Mekatronika Politeknik Aceh. Fokus p ini adalah bagaimana PLC mampu mengendalikan pompa air sebagai penyalur air dalam proses pengisian. Selain itu PLC mampu mengendalikan solenoid dalam mengencangkan tutup botol dan memanfaatkan konveyor mini sebagai pembawa botol serta sensor proximity sebagai pendeteksi botol.

\section{Tinjauan Pustaka}

\subsection{Programmable Logic Controller (PLC)}

Programmable logic controller (PLC) adalah sebuah perangkat kontrol yang dirancang untuk menggantikan sistem kontrol relay elektrik berbasis relay yang mulai digunakan pada tahun 1970- an [5]. Keunggulan PLC dibanding sistem konvensional yaitu lebih mudah dalam instalasi karena pengkabelan PLC yang sederhana, lebih mudah dalam menemukan kesalahan dan kerusakan, serta jumlah relay yang diperlukan dapat dikurangi hingga tinggal seperlimanya saja [5][6].

PLC terdiri dari beberapa bagian utama yaitu bagian input modul, output modul serta Central Processing 
Unit (CPU)[7]. Input modul merupakan bagian PLC yang terhubung dengan komponen luar yang memberikan masukan kepada CPU seperti push button, sensor, limit switch, dll. Output modul merupakan bagian PLC yang menerima sinyal dari keluaran CPU ke komponen penggerak seperti motor, relay, buzzer, solenoid valve, dll[7]. Bagian -bagian tersebut dapat ditunjukkan seperti pada gambar 1.

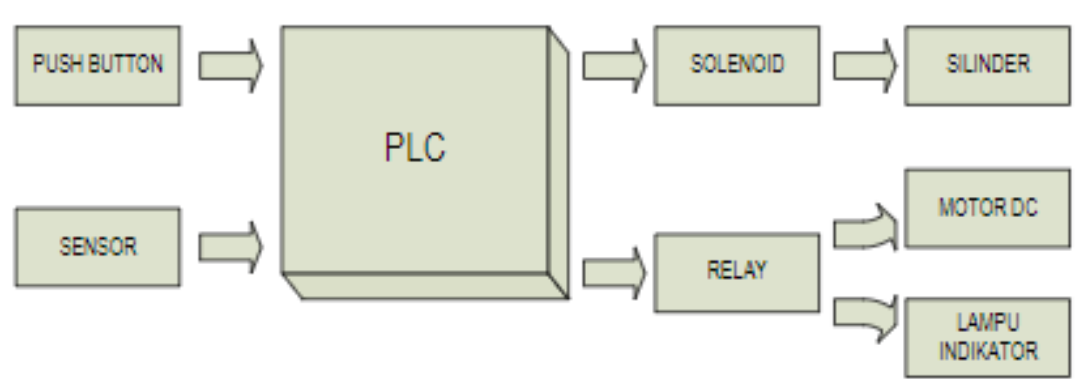

Gambar 1. Bagian PLC beserta komponen masukan dan keluarannya [8]

\subsection{Modul Praktikum}

Modul praktikum merupakan media atau alat yang digunakan dalam pembelajaran praktikum. Modul praktikum menjadi sangat penting karena menjadi salah satu cara agar pembelajaran suatu perkuliahan praktikum berjalan dengan baik [9]. Dengan adanya modul praktikum, pembelajaran praktik menjadi lebih nyata karena langsung berinteraksi dengan alat. Dengan demikian mahasiswa tidak hanya berimajinasi melaksanakan pembelajaran praktikum dengan simulasi saja melalui perangkat lunak, melainkan langsung melihat dan mengoperasikan modul praktikum.

Modul juga dapat diartikan sebagai petunjuk praktikum yang disusun dengan format tertentu. Dalam modul praktikum tersebut terdapat petunjuk dalam melaksanakan praktikum, peralatan yang digunakan, teori dasar, rangkaian percobaan dan sebagainya. Gambar 2 menunjukkan contoh modul praktikum yang digunakan dalam pembelajaran PLC[10].

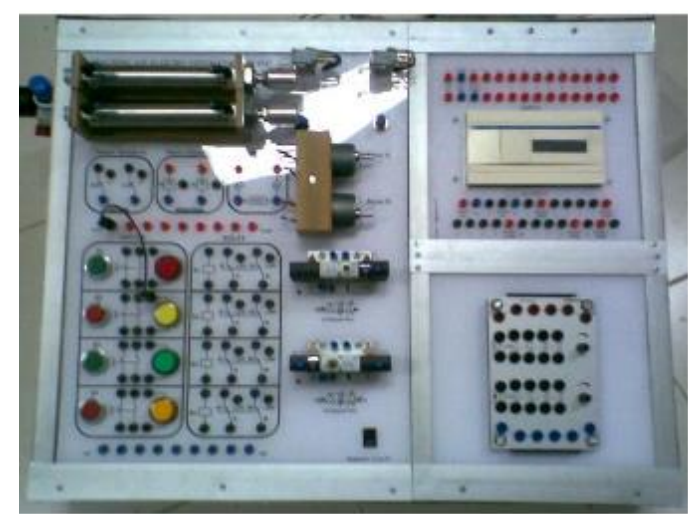

Gambar 2. Modul prakatik PLC [8]

\section{Metode Penelitian}

\subsection{Perancangan Mekanik}

Pada bagian ini akan dijelaskan mengenai perancangan mekanik keseluruhan dalam perencanaan pembuatan Prototipe pengisi air dan penutup botol otomatis berbasis PLC. Perancangan mekanik alat ini ditunjukkan pada gambar 3 . 


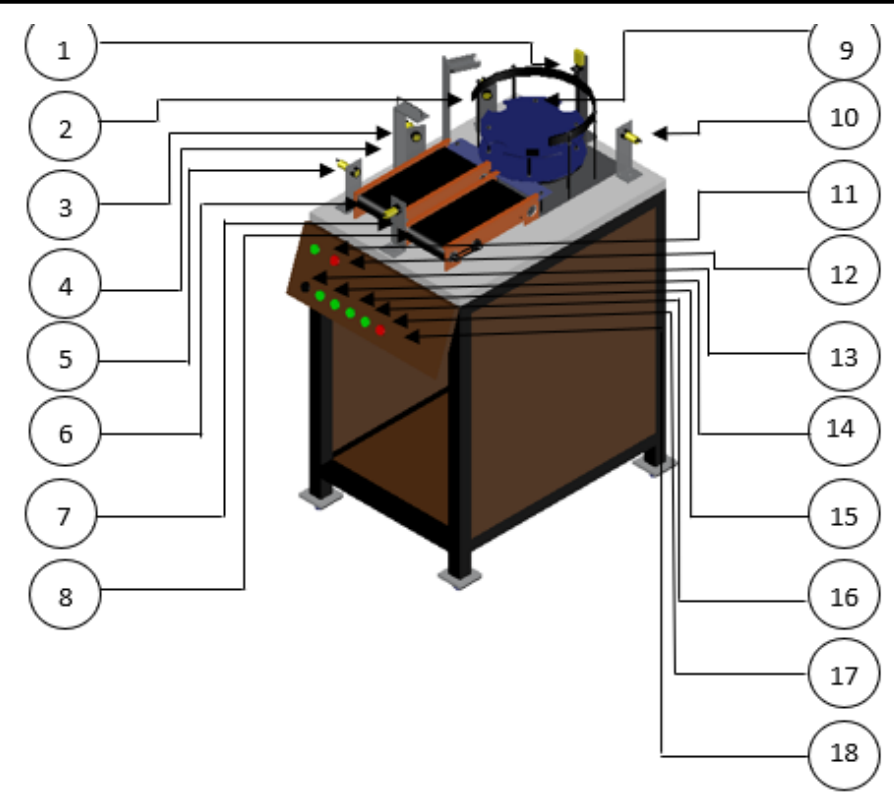

Gambar 3. Perancangan Mekanik

Rancangan mekanik dibuat menggunakan Software Autocad dengan satuan ukuran Milimeter, alat ini menggunakan Alumunium Profile sebagai alas dari station pada modul praktikum, rangka meja menggunakan besi Hollow ukuran $3 \mathrm{~mm} \times 3 \mathrm{~mm}$, Komponen-Komponen utama pada Prototipe pengisi air dan penutup Botol Otomatis Berbasis PLC dijelaskan sebagai berikut:

1. Station Penutupan Botol

Station ini berfungsi untuk proses penutupan botol menggunakan 2 buah komponen yaitu Motor DC 4 dan Solenoid Door lock

2. Sensor Proximity 2

Sensor ini berfungsi untuk memicu piringan menyala dan memicu konveyor 1 untuk berhenti.

3. Sensor Proximty 3

Sensor ini berfungsi untuk memicu konveyor 1 berhenti sementara untuk melakukan proses pengisian air.

4. Station pengisian air

Station ini berfungsi untuk proses pengisian air pada botol, stasiun ini menggunakan sebuah komponen yaitu mini dc water pump

5. Sensor Proximity 4

Sensor ini berfungsi sebagai pemicu konveyor 1 menyala

6. Konveyor 1

Konveyor 1 merupakan media penghantar botol menuju ke stasiun pengisian air dan piringan, stasiun ini menggunakan komponen Motor DC 1

7. Sensor Proximity 5

Sensor ini berfungsi saat mengkalibrasi piringan

8. Konveyor 2

Merupakan media penghantar botol ketika sudah selesai melewati seluruh stasiun yang diperlukan, Konveyor 2 menggunakan komponen berupa Motor Dc 1

9. Piringan

Merupakan media penghantar botol menuju stasiun penutupan dan konveyor 1, piringan menggunakan komponen berupa Motor Dc 1

10. Sensor Proximity 1

Berfungsi sebagai pemicu stasiun penutupan menyala dan memberhentikan piringan sementara

11. Lampu Indikator 1

Merupakan lampu indikator alat menyala

12. Lampu Indikator 2

Merupakan lampu indikator ketika tombol emergency di tekan

13. Power Selector 


\footnotetext{
Merupakan media untuk menghidupkan alat

14. Tombol 1

Adalah tombol untuk mengkalibrasi piringan

15. Tombol 2

Adalah tombol untuk menghidupkan konveyor 1

16. Tombol 3

Adalah tombol untuk menghidupkan konveyor 2

17. Tombol 4

Adalah tombol untuk menghidupkan pompa air

18. Tombol Emergency

Merupakan tombol darurat untuk mematikan sistem secara keseluruhan

\subsection{Perancangan Elektrik}

Pada bagian ini akan dijelaskan mengenai perancangan elektrik keseluruhan dalam perencanaan pembuatan Prototipe pengisi air dan penutup botol otomatis berbasis PLC untuk modul praktikum. Gambar 4 merupakan perancangan keseluruhan elektrik pada prototipe pengisi air dan penutup botol otomatis berbasis PLC. Sumber tegangan yang digunakan sensor sebesar 5 Volt DC, menggunakan komponen relay agar keluaran tegangan sensor sesuai dengan kebutuhan pada input PLC yaitu sebesar 24 Volt DC sehingga dapat dibaca oleh PLC. Keluaran PLC yang memiliki tegangan sebesar 24 Volt DC berfungsi untuk menggerakkan relay agar actuator alat dialiri oleh tegangan yang diperlukan sehingga dapat bekerja dengan baik, penggunaan relay pada output PLC adalah untuk mencegah kerusakan pada PLC jika terjadi kesalahan teknis pada alat ini. rangkaian elektrik di atas juga di lengkapi dengan marking atau tanda agar mempermudah proses maintenance.
}

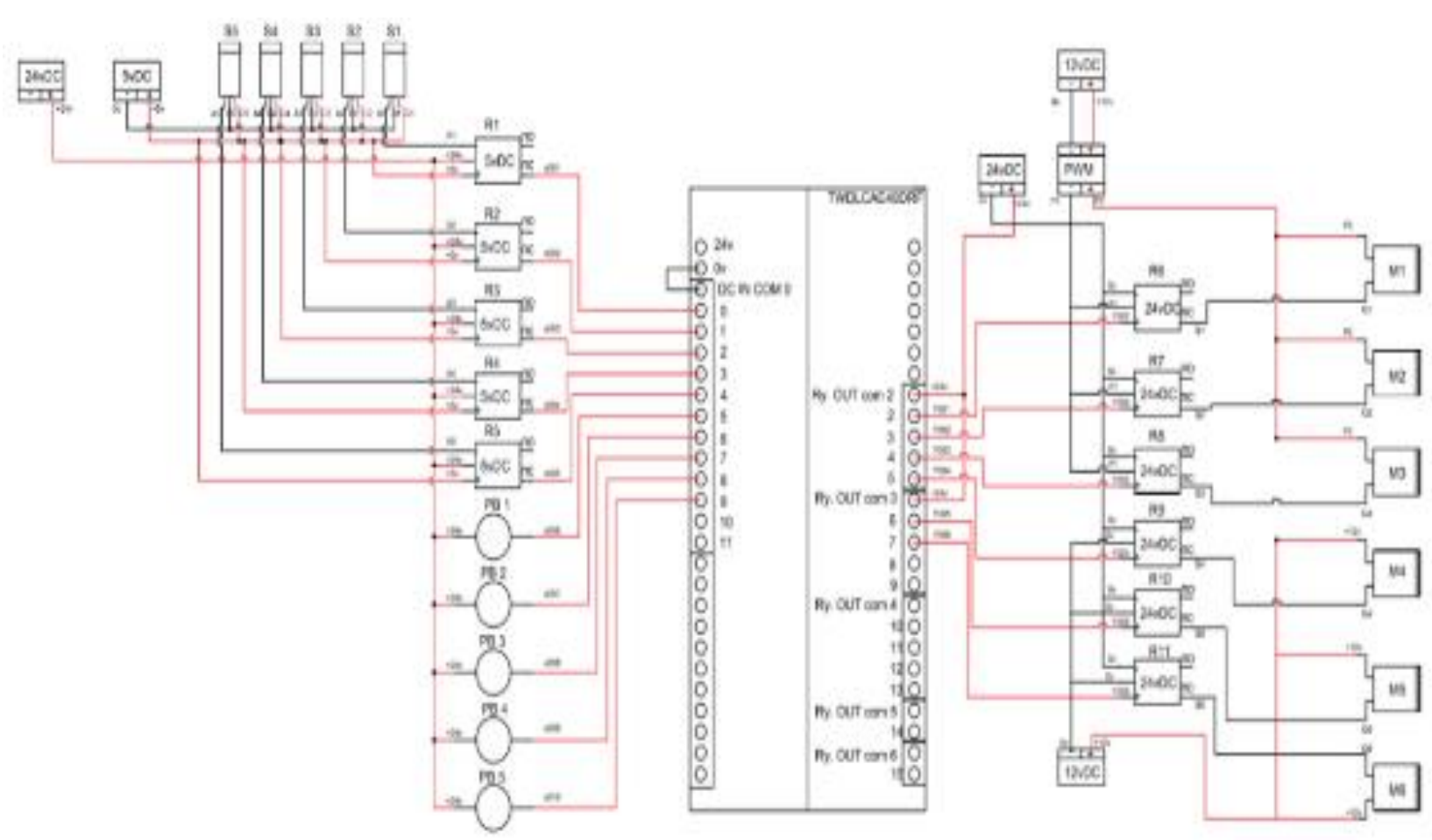

Gambar 4. Perancangan elektrik prototipe pengisi air dan penutup botol otomatis berbasis PLC 


\subsection{FlowChart Prototipe Pengisi dan Penutup Botol Otomatis Berbasis PLC}

Cara kerja alat pengisi dan penutup botol otomatis berbasis PLC pada penelitian ini ditunjukkan pada gambar 5 .
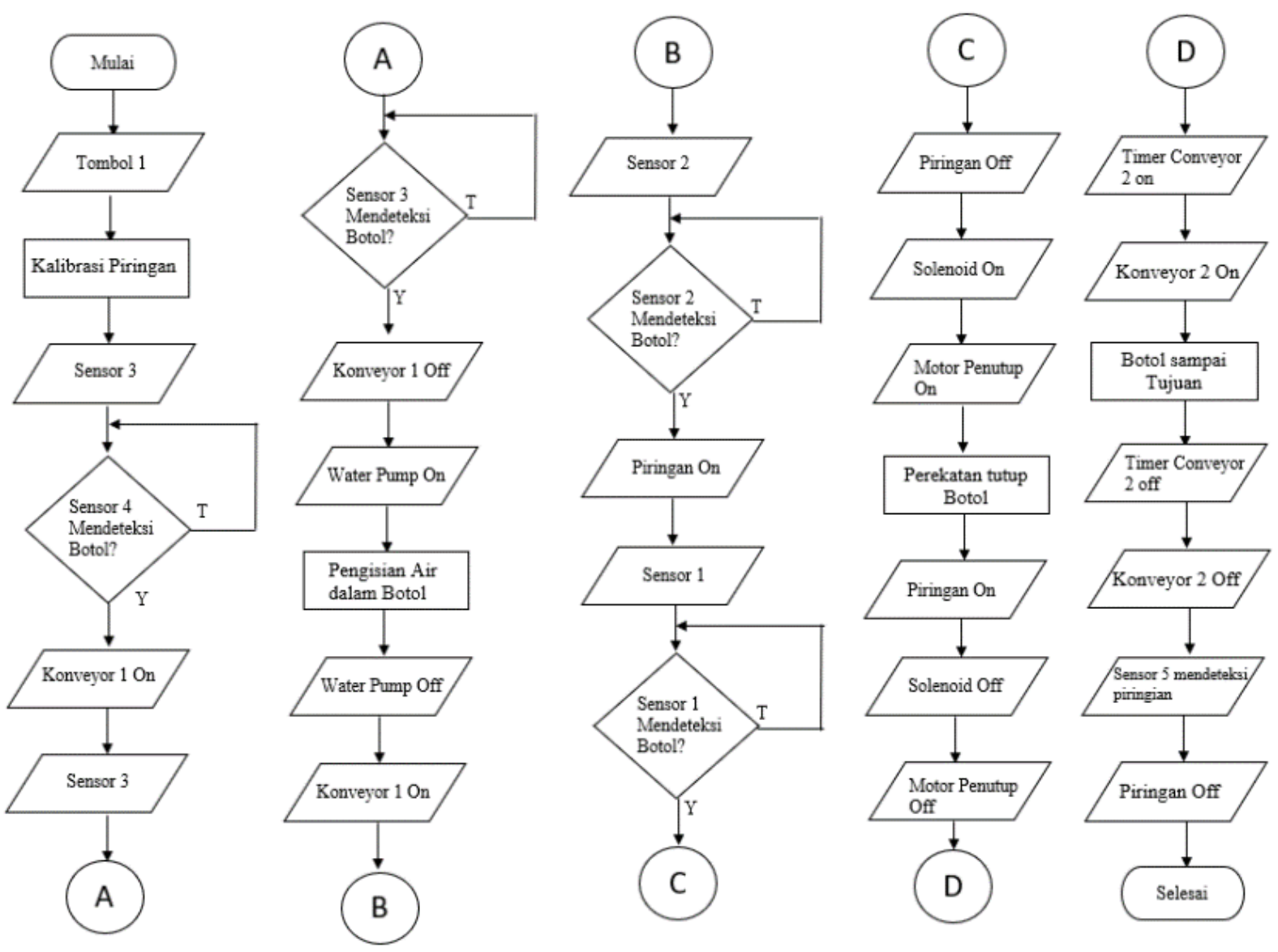

Gambar 5. Flowchart prototype pengisi air dan penutup botol otomatis berbasis PLC untuk modul praktikum

Flowchart pada gambar 5 dapat dijelaskan sebagai berikut:

1. Sistem dinyalakan

2. Mengkalibrasi piringan dengan menekan tombol 1.

3. Sensor 4 akan mendeteksi botol kemudian akan menyalakan konveyor.

4. Botol akan terdeteksi oleh sensor 3 kemudian akan mematikan konveyor 1 sesaat untuk memberi waktu Mini DC Water Pump mengisi air, setelah proses pengisian air selesai maka konveyor akan kembali hidup.

5. Sensor 2 akan mendeteksi botol dan mematikan konveyor 1 kemudian menghidupkan piringan maka botol akan menuju ke stasiun penutupan botol.

6. Sensor 1 akan mendeteksi botol dan mematikan piringan kemudian memulai proses penutupan botol dengan mengaktifkan motor penutup dan solenoid.

7. Setelah proses penutupan selesai piringan akan kembali aktif dan akan mengaktfikan konveyor 2 selama waktu yang telah ditentukan.

8. Botol akan menuju ke konveyor 2 .

9. Sensor 5 akan mendeteksi piringan yang akan mematikan piringan. 
10. Botol sampai ke tempat tujuan dan selesai.

\section{Hasil dan Pembahasan}

\subsection{Hasil Penelitian}

Setelah selesai dalam proses perancangan dan pembuatan alat maka hasil akhir yang diperoleh adalah seperti pada gambar 6 .

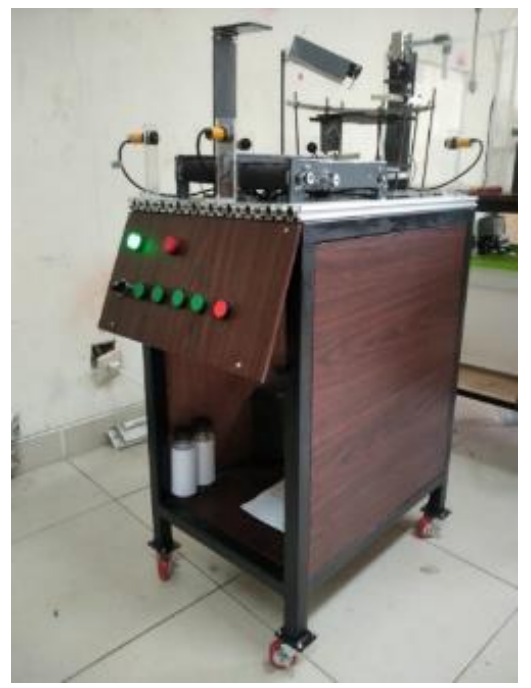

Gambar 6. Hasil Perancangan dan pembuatan alat

\subsection{Pengujian Alat}

\subsubsection{Pengujian Monitoring Program Proses Pengisian Air}

\section{A. Tujuan}

Pengujian Monitoring Program Proses Pengisian Air bertujuan untuk melihat apakah program sudah sesuai dengan FlowChart yang telah ditentukan.

B. Alat dan Bahan

Alat dan bahan yang digunakan pada percobaan ini yaitu:

1. Software Twidosuite

2. Komputer/Laptop

3. Kabel USB to Serial DB9

C. Langkah Pengujian

Langkah pengujian sebagai berikut:

1. Siapkan Alat.

2. Buka Software TwidoSuite

3. Buatlah Ladder PLC

4. Sambungkan kabel USB to Serial DB9 ke PLC

5. Download Program Menuju PLC

6. Amati Ladder Ketika alat sedang bekerja 


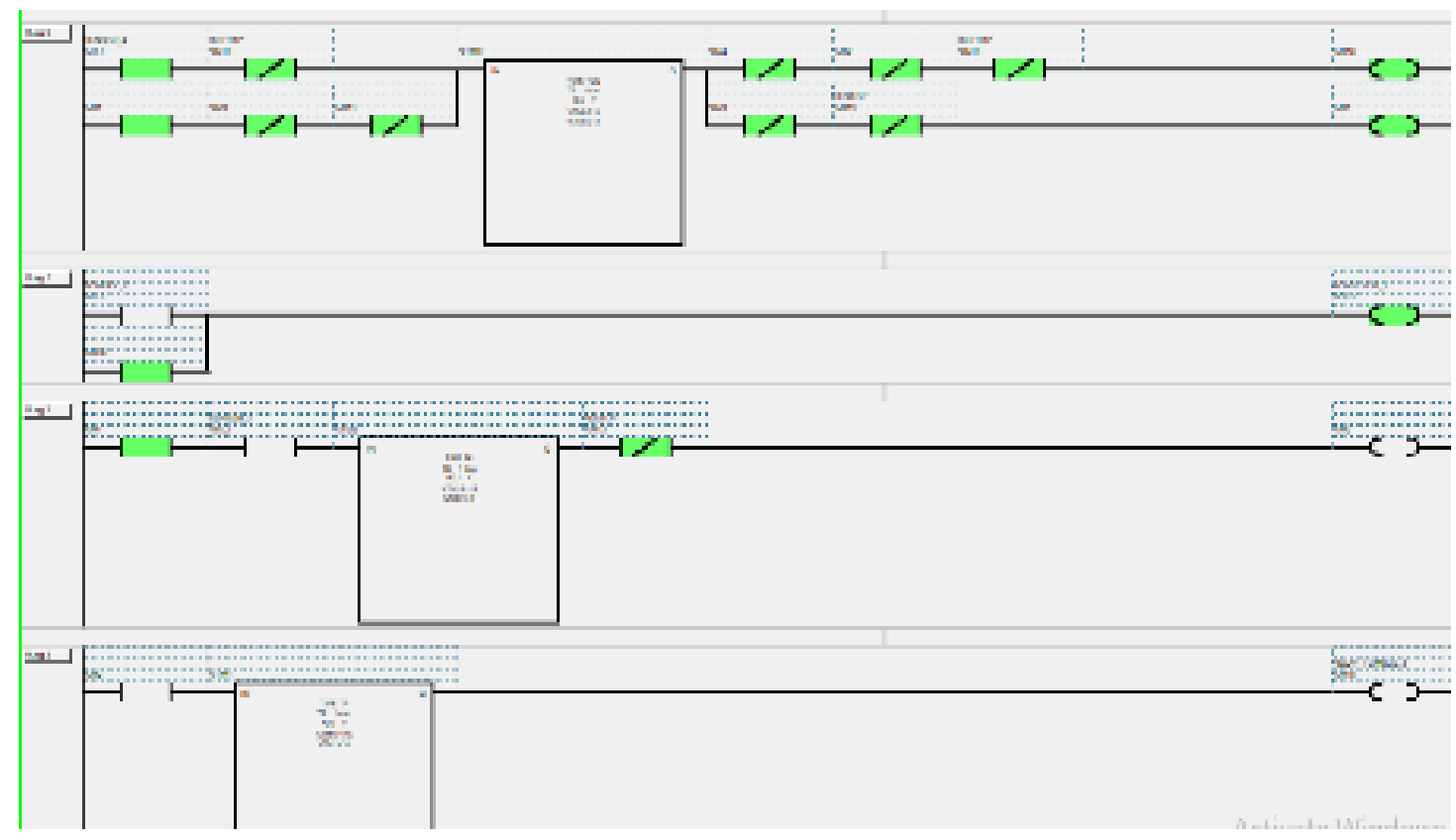

Gambar 7. Program proses pengisian air

Dapat dilihat dari gambar 7 ketika sensor 4 mendeteksi botol maka timer akan menghitung selama 3 detik kemudian akan mengaktifkan internal relay yang beralamat \% 1 dan $\% \mathrm{M} 16$, Internal Relay \% 1 akan mengaktifkan konveyor secara terus menerus, ketika alamat masukan \%I0.2 atau sensor 3 mendeteksi objek maka timer akan mulai menghitung selama 17 detik untuk mengaktifkan internal Relay \%M2 yang berfungsi untuk menghentikan konveyor dan juga menyalakan pompa air selama 14 detik, setelah timer selesai menghitung maka konveyor akan berjalan kembali.

\section{Analisa}

Dari pengujian monitoring program proses pengisian air dapat di Analisa berupa, jika sensor 4 tidak mendeteksi adanya objek selama 3 detik maka konveyor 1 tidak akan menyala namun konveyor 1 dapat dinyalakan secara manual dengan cara menekan tombol 2 yang beralamat \%I0.6, untuk program pengisian air pompa air tidak akan menyala jika sensor 3 tidak mendeteksi adanya objek, pompa air dapat di aktifkan secara manual dengan menekan tombol 4 namun sensor 3 harus tetap mendeteksi adanya objek.

\subsubsection{Pengujian Waktu Pompa Air}

\section{A. Tujuan}

Pengujian waktu pompa air bertujuan untuk mendapatkan waktu yang cukup agar botol terisi air dengan takaran yang telah ditentukan.

B. Alat dan Bahan

Alat dan bahan yang digunakan pada pengujian ini yaitu:

\section{PLC Schneider TWDLCAE40DRF.}

2. Software Twido Suite.

3. Botol Ukuran $250 \mathrm{ml}$.

4. Mini dc water pump.

\section{Langkah Pengujian}

Langkah pengujian sebagai berikut:

1. Nyalakan PLC Schneider TWDLCAE40DRF.

2. Jalankan Software twidosuite.

3. Buat program timer untuk alamat pompa DC.

4. Uji coba secara berulang hingga mendapatkan waktu yang pas. 


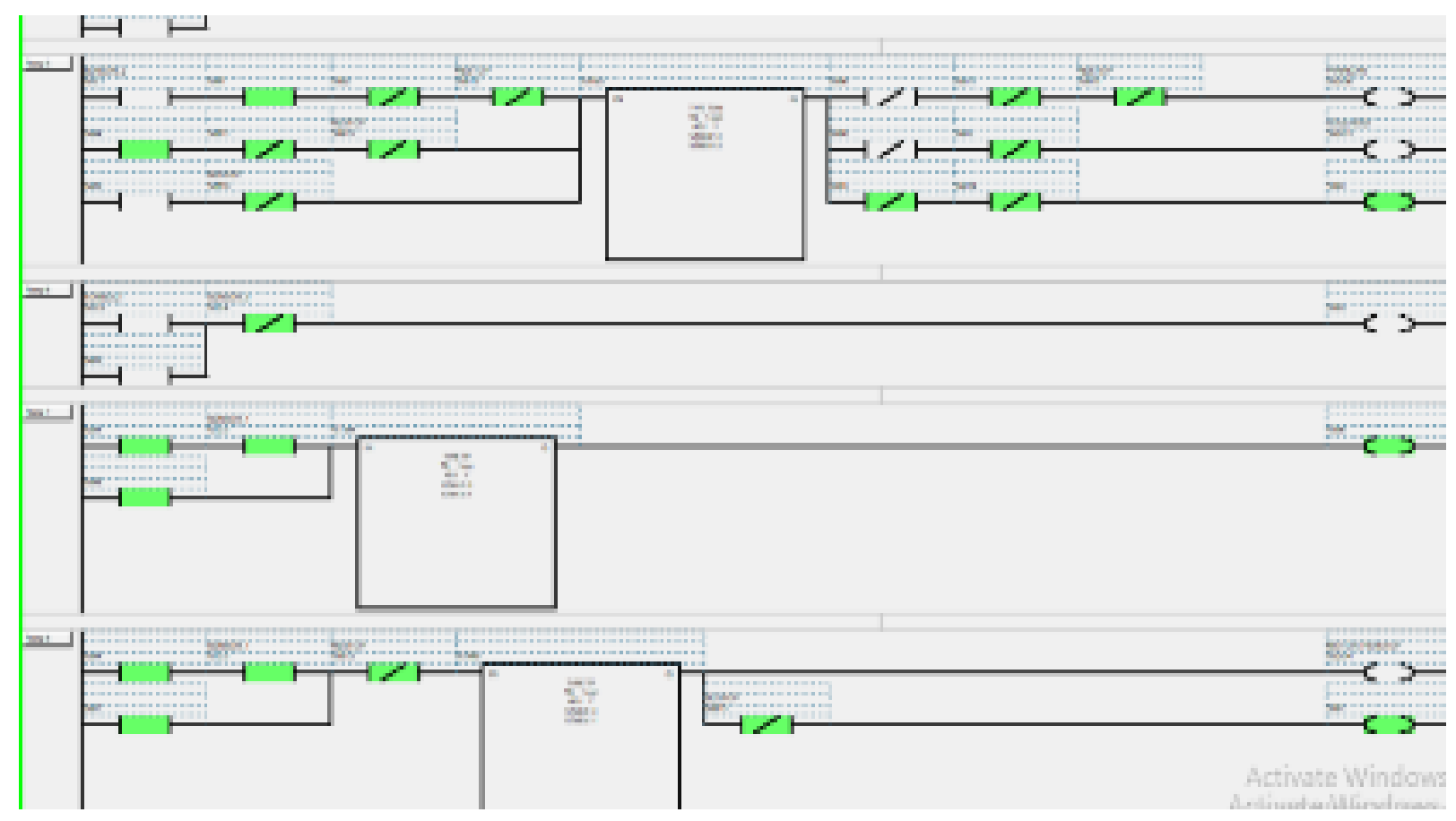

Gambar 8. Program Proses Penutupan Botol

Pada Gambar86 dapat dilihat bahwa jika botol telah selesai melewati proses pengisian air maka internal relay \%M1 akan aktif, dan jika sensor 2 yang beramat \%I0.1 mendeteksi adanya botol maka timer akan menghitung selama 2 detik kemudian akan mengaktifkan piringan dengan alamat \%Q0.6, kemudian jika sensor 1 dengan alamat \% I0.0 mendeteksi objek maka akan mematikan piringan dengan menggunakan internal relay \%M6 selama 3 detik. Setelah timer selesai menghitung waktu selama 3 detik maka piringan akan kembali menyala.

\section{Analisa}

Dari hasil pengujian monitoring program proses penutupan botol dapat di analisa bahwasanya proses penutupan botol telah sesuai dengan Flowchart yang di tentukan, namun pada proses penutupan botol tidak dapat dilakukan secara manual, botol harus melewati proses pengisian air terlebih dahulu untuk dapat melakukan proses penutupan botol, proses penutupan memerlukan waktu sekitar 3 detik untuk perekatan tutup botol.

\subsubsection{Pengujian Keseluruhan Sistem}

A. Tujuan

Pengujian keseluruhan sistem bertujuan untuk mengetahui apakah sistem mampu berjalan sesuai dengan yang diinginkan.

\section{B. Alat dan Bahan}

Alat dan bahan yang digunakan pada pengujian ini yaitu:

1. PLC Schneider TWDLCAE40DRF.

2. Software TwidoSuite.

3. Sensor Infrared E18-D80NK. 


\section{Botol Air $250 \mathrm{ml}$.}

C. Langkah Pengujian

Langkah pengujian sebagai berikut:

1. Siapkan Alat.

2. Masukkan Program Ladder.

3. Amati pergerakan alat.

Pada Tabel 1 dari pengujian keseluruhan sistem dapat dilihat tingkat keberhasilan pengujian lebih banyak dibandingkan dengan kegagalan, pada percobaan pertama dan kedua seluruh sistem dapat bekerja dengan baik, namun pada percobaan ketiga dan keempat sistem mengalami kegagalan pada proses penutupan botol, kegagalan yang terjadi adalah tutup botol jatuh dari atas botol dan tidak bisa dieratkan, pada percobaan kelima dan keenam sistem kembali bekerja dengan baik.

\begin{tabular}{|c|c|c|c|c|c|}
\hline No & Konveyor 1 & $\begin{array}{c}\text { Pompa } \\
\text { Air }\end{array}$ & $\begin{array}{c}\text { Penutupan } \\
\text { botol }\end{array}$ & Konveyor 2 & Hasil \\
\hline 1 & $\begin{array}{l}\text { Berhasil } \\
\text { membawa } \\
\text { botol menuju } \\
\text { piringan }\end{array}$ & $\begin{array}{l}\text { Berhasil } \\
\text { mengisi } \\
\text { sesuai } \\
\text { ketentuan }\end{array}$ & $\begin{array}{l}\text { Berhasil } \\
\text { mempererat } \\
\text { tutup Botol }\end{array}$ & $\begin{array}{l}\text { Berhasil } \\
\text { membawa } \\
\text { botol yang } \\
\text { telah selesai } \\
\text { diproses }\end{array}$ & Berhasil \\
\hline 2 & $\begin{array}{l}\text { Berhasil } \\
\text { membawa } \\
\text { botol menuju } \\
\text { piringan }\end{array}$ & $\begin{array}{l}\text { Berhasil } \\
\text { mengisi } \\
\text { sesuai } \\
\text { ketentuan }\end{array}$ & $\begin{array}{l}\text { Berhasil } \\
\text { mempererat } \\
\text { tutup Botol }\end{array}$ & $\begin{array}{l}\text { Berhasil } \\
\text { membawa } \\
\text { botol yang } \\
\text { telah selesai } \\
\text { diproses }\end{array}$ & Berhasil \\
\hline 3 & $\begin{array}{l}\text { Berhasil } \\
\text { membawa } \\
\text { botol menuju } \\
\text { piringan }\end{array}$ & $\begin{array}{l}\text { Berhasil } \\
\text { mengisi } \\
\text { sesuai } \\
\text { ketentuan }\end{array}$ & $\begin{array}{l}\text { Gagal } \\
\text { mempererat } \\
\text { tutup Botol }\end{array}$ & $\begin{array}{l}\text { Berhasil } \\
\text { membawa } \\
\text { botol yang } \\
\text { telah selesai } \\
\text { diproses }\end{array}$ & Gagal \\
\hline 4 & $\begin{array}{l}\text { Berhasil } \\
\text { membawa } \\
\text { botol menuju } \\
\text { piringan }\end{array}$ & $\begin{array}{l}\text { Berhasil } \\
\text { mengisi } \\
\text { sesuai } \\
\text { ketentuan }\end{array}$ & $\begin{array}{l}\text { Gagal } \\
\text { mempererat } \\
\text { tutup Botol }\end{array}$ & $\begin{array}{l}\text { Berhasil } \\
\text { membawa } \\
\text { botol yang } \\
\text { telah selesai } \\
\text { diproses }\end{array}$ & Gagal \\
\hline 5 & $\begin{array}{l}\text { Berhasil } \\
\text { membawa } \\
\text { botol menuju } \\
\text { piringan }\end{array}$ & $\begin{array}{l}\text { Berhasil } \\
\text { mengisi } \\
\text { sesuai } \\
\text { ketentuan }\end{array}$ & $\begin{array}{l}\text { Berhasil } \\
\text { mempererat } \\
\text { tutup Botol }\end{array}$ & $\begin{array}{l}\text { Berhasil } \\
\text { membawa } \\
\text { botol yang } \\
\text { telah selesai } \\
\text { diproses }\end{array}$ & Berhasil \\
\hline 6 & $\begin{array}{l}\text { Berhasil } \\
\text { membawa } \\
\text { botol menuju } \\
\text { piringan }\end{array}$ & $\begin{array}{l}\text { Berhasil } \\
\text { mengisi } \\
\text { sesuai } \\
\text { ketentuan }\end{array}$ & $\begin{array}{l}\text { Berhasil } \\
\text { mempererat } \\
\text { tutup Botol }\end{array}$ & $\begin{array}{l}\text { Berhasil } \\
\text { membawa } \\
\text { botol yang } \\
\text { telah selesai } \\
\text { diproses }\end{array}$ & Berhasil \\
\hline
\end{tabular}

Tabel 1. Hasil Pengujian keseluruhan sistem

\section{Analisa}

Keberhasilan setiap percobaan tergantung pada proses penutupan botol dikarenakan proses peletakan tutup botol di atas botol belum berhasil sehingga tutup botol terjatuh. Setelah dilakukan analisa maka ditemukan penyebab permasalahan tersebut dikarenakan bagian alat untuk meletakkan tutup botol tidak searah dengan pergerakan botol pada piringan, maka setelah dilakukan penyesuaian, percobaan kembali berhasil, namun alat tidak dapat menutup botol dengan kencang dikarenakan alat ini masih menggunakan solenoid sebagai penekan tutup botol dan motor DC 5 Volt sebagai pemutar tutup botol, ketika dilakukan percobaan harus diawasi dengan berhati-hati untuk mencegah air tumpah yang dapat merusak sistem, 


\section{Kesimpulan}

Berdasarkan hasil pengujian dan analisa dapat ditarik kesimpulan bahwasanya alat ini dapat digunakan untuk modul praktikum mahasiswa karena dapat dioperasikan dengan baik. semua komponen berfungsi dengan baik. Alat ini dapat melakukan pengisian dan penutupan dengan baik dengan memasukkan program PLC sesuai dengan flowchart kerja alat. Alat ini mampu mengisi air ke dalam botol ukuran $250 \mathrm{ml}$ dalam waktu $13 \mathrm{~s}$ sampai 14s. Sensor infrared E18-D80NK mampu mendeteksi objek logam maupun non logam dengan jarak yang cukup jauh. Alat ini masih memiliki beberapa kekurangan yaitu hanya dapat menutup botol satu persatu, volume air yang tidak konsisten, dan juga kerapatan penutupan tutup botol yang tidak begitu kencang. Beberapa kekurangan ini dapat menjadi dasar untuk pengembangan penelitian selanjutnya

\section{Daftar Pustaka}

[1] D. Satria, Z. Zainal, and T. Hidayat, "Plant Watering System Based on the Internet of Thing," J. Nas. Komputasi dan Teknol. Inf., vol. 1, no. 1, 2018.

[2] A. K. Amrullah, "Alat Pengisian Air di Botol Menggunakan Arduino," vol. 5, no. 1, pp. 128-131, 2021.

[3] S. Rumalutur and S. L. Allo, "Sistem Kontrol Otomatis Pengisian Cairan Dan Penutup Botol Menggunakan Arduino Uno Rev 1.3," Electro Luceat, vol. 5, no. 1, pp. 23-34, 2019.

[4] F. G. Airlangga, A. Triwiyatno, and Sumardi, "Perancangan Sistem Automasi Pada Pengemasan Susu Dalam Botol Dengan Programmable Logic Controller (PIc) Omron Cp1E Terhadap Purwarupa Filling Bottle and Capping Machine," Transient, vol. 6, no. 1, pp. 103-109, 2017.

[5] Balza Achmad, Pemrograman PLC Menggunakan Simulator. Yogyakarta: Andi, 2007.

[6] T. D. I. Bei, "Universitas 17 Agustus 1945 Jakarta," E - ISSN, J. Kaji. Tek. elektro, vol. 2014, no. April, p. 2014, 2014.

[7] R. T. Bangun and H. Fahmi, "Perancangan Sistem Perangkap Hama Tanaman Petani Otomatis Menggunakan Modul Mikrokontroler Arduino," J. Nas. Komputasi dan Teknol. Inf., vol. 4, no. 1, 2021.

[8] R. Ikhsan, Y. Yanti, P. Aceh, U. S. Mekkah, P. R. Kareng, and B. Aceh, "Rancang bangun teaching aid elektro pneumatik," vol. 8, no. 1, pp. 9-14, 2019.

[9] M. Muslim, "Pengembangan Modul Praktikum Elektronika Berbasis Proyek Untuk Meningkatkan Pemahaman Mahasiswa," vol. 4, no. 2, pp. 150-156, 2017.

[10] H. H. Abrianto, K. Sari, and I. Irmayani, "Sistem Monitoring Dan Pengendalian Data Suhu Ruang Navigasi Jarak Jauh Menggunakan WEMOS D1 Mini,” J. Nas. Komputasi dan Teknol. Inf., vol. 4, no. 1, pp. 38-49, 2021. 